\title{
How parameter specification of an Earth system model of intermediate complexity influences its climate simulations
}

\author{
Yuhan Shi ${ }^{1,2}$, Wei Gong ${ }^{1,2^{*}}$ (D), Qingyun Duan ${ }^{1,2}$, Jackson Charles $^{3}$, Cunde Xiao ${ }^{1}$ and Heng Wang ${ }^{1,2}$
}

\begin{abstract}
Earth system models (ESMs) consist of parameterization schemes based on one's perception of how the Earth system functions. A typical ESM contains a large number of parameters (i.e., the constants and exponents in the parameterization schemes) whose specification can have a significant impact on an ESM's simulation capabilities. Sensitivity analyses (SA) is an important tool for assessing how parameter specification influences model simulations. In this study, we used an Earth system model of intermediate complexity (EMIC) - LOVECLIM as an example to illustrate how SA methods can be used to identify the most sensitive parameters that control the simulations of several key global water and energy cycle variables, including global annual mean absolute surface air temperature $\left(T_{\mathrm{G}}\right)$, precipitation and evaporation over the land and over the oceans $\left(P_{\mathrm{L}}, P_{\mathrm{O}}, E_{\mathrm{L}}, E_{\mathrm{O}}\right)$, and land runoff $\left(R_{L}\right)$. We also demonstrate how judiciously specifying model parameters can improve the simulations of those variables. Three SA methods MARS, RF, and sparse PCE-based Sobol' method were used to evaluate a pool of 25 adjustable parameters chosen from land, atmosphere, and ocean components of LOVECLIM and their results were intercompared to ensure robustness of the results. It is found that with different parameter specification, $T_{G}$ can vary from 10 to $20{ }^{\circ} \mathrm{C}$, and the values of $P_{L}, P_{\mathrm{O}}, E_{\mathrm{L}}$, and $E_{\mathrm{O}}$ can change by more than $100 \%$. An interesting observation is that the value of $R_{\mathrm{L}}$ vary from 13,000 to $35,000 \mathrm{~km}^{3}$, far below the observed climatological value of $40,000 \mathrm{~km}^{3}$, indicating a model structural deficiency in representing land runoff by LOVECLIM which must be corrected to obtain more reasonable global water budgets. We also note that parameter sensitivities are significantly different at different latitudes. Finally, we showed that global water and energy cycle simulations can be significantly improved by even a crude automatic parameter tuning, indicating that parameter optimization can be a viable way to improve ESM climate simulations. The results from this study should help us to understand the parameter uncertainty of a full-scale ESM.
\end{abstract}

Keywords: Parameter sensitivity analysis, Earth system model of intermediate complexity, LOVECLIM, Parametric uncertainty

\section{Introduction}

Earth system models (ESMs) are an indispensable tool for gaining an understanding on how the climate system works and how its various components such as land, atmosphere, and oceans interact with each other. They have been used extensively to simulate the past and future

\footnotetext{
* Correspondence: gongwei2012@bnu.edu.cn

${ }^{1}$ State Key Laboratory of Earth Surface Processes and Resource Ecology, Faculty of Geographical Science, Beijing Normal University, Beijing 100875, China

${ }^{2}$ Institute of Land Surface System and Sustainable Development, Faculty of Geographical Science, Beijing Normal University, Beijing 100875, China Full list of author information is available at the end of the article
}

climatic processes and events. The simulation and predictive capabilities of ESMs are influenced by several factors such as the specification of model forcings, the specification of initial and boundary conditions, and the representation of model physics. In the past, much attention has been paid to develop various models of different complexities. Over the recent years, researchers become increasingly aware that tuning is an essential aspect of climate modeling (Hourdin et al. 2017). The purpose of tuning is to reduce the distance between model results and the observed climate by adjusting the values of various parameters. It has been shown that the simulation capability of a 
climate model may be enhanced significantly by adjusting the values of even one or two of its model parameters (Collins et al. 2006; Gent et al. 2011; Sanderson et al. 2008; Tebaldi and Knutti 2007; Williamson et al. 2013).

In fields such as hydrology and engineering, parameter tuning or optimization methods have been commonly used to estimate model parameters. However, parameter optimization of climate models is an enormous computational task for the following reasons: (1) optimization of climate model parameters is a high-dimensional problem because climate models usually contain a large number of adjustable parameters (dozens or even hundreds of parameters), and the number of model experiments to optimize those parameters is exponentially proportional to the dimensionality; (2) climate models simulate many climatic variables (e.g., temperature, precipitation, evaporation, wind speed, and pressure), and the optimization problem must be framed as a multiobjective optimization problem, which further increases the number of model experiments needed to identify optimal parameter solutions; and (3) climate models are expensive to run because they must be run globally and cover time span over many years. Even with today's most advanced supercomputers, the amount of computational resources required for optimizing the parameters of a climate model can still be prohibitive.

Climate models vary in complexity from simple conceptual models to sophisticated earth system models (Claussen et al. 2002; Eby et al. 2013). Simple conceptual models are useful in developing and exploring the variability of individual processes in the climate system. However, these models only describe a very limited number of processes and variables. Current state-of-the-art Earth system models (ESMs) provide very detailed descriptions of the Earth system, including more feedbacks and processes. Because of their complexities, the number and length of simulations that can be conducted are limited by the availability of computational resources and it is not practical to perform parameter estimation exercises on full-scale ESMs. Another class of models, known as the Earth system models of intermediate complexity (EMICs), helps bridge the gap between the simplest and most complex climate models (Claussen et al. 2000). EMICs provide a fairly complete description of the Earth system, including almost all components of the Earth system, but this often occurs in an idealized manner or at a lower resolution than the models described above. To explore the various feedbacks among different components of the climate system, EMICs simulate long-term climate changes with parameterization schemes to simplify the various processes and details of the climate system. These models are usually applied to certain scientific questions, such as understanding climate feedbacks on millennial time scales or exploring sensitivities in which long model integrations or large ensembles are required (Claussen et al.
2002; Petoukhov et al. 2005). To a certain extent, EMICs combine the advantages of simple conceptual models and Earth system models and overcome their disadvantages. As computing power increases in the future, this model class will continue to advance in terms of resolution and complexity. This study uses an EMIC model as an example to study how parameter specification affects climate model simulations and to explore potentials for improving climate model simulation through parameter perturbations.

Despite the differences between EMICs and ESMs in model conceptualization and structures, we hope the experiences with parameter specification methods (such as uniform sampling, sensitivity analysis, etc.) of simple and computational affordable EMICs can be applied to fullscale ESMs to improve ESMs performance with less computational resources.

In our previous studies (Duan et al. 2017; Gan et al. 2014; Gong and Duan 2017; Gong et al. 2015; Gong et al. 2016a; Gong et al. 2016b), an uncertainty quantification (UQ) framework was developed to quantify the uncertainty of large, complex dynamic system models, such as land-surface, weather, and climate models, which include many physical processes and cost a substantial amount of computational resources to run. The uncertainty quantification framework includes the following steps: (1) using parameter screening to reduce the number of adjustable parameters, (2) building a surrogate model to emulate the response surfaces of the original model to the variation in the adjustable parameters, and (3) running the surrogate model with the sensitive parameters to optimize the original model. Sensitivity analysis (SA) methods have been shown to be very effective for parameter screening to determine the parameters which exert significant influence on climate model simulations of interested variables (Gutiérrez et al. 2009; Ratto et al. 2012; Shahsavani and Grimvall 2011). SA methods use a design of experiment (DoE) approach to sample model parameters within a feasible range and quantify the influence of each adjustable parameters to the model output. The parameters that have significant influence to model outputs are screened out as important parameters. So far, there have been numerous studies that have used SA methods to examine the parametric sensitivity of hydrology (Gupta and Razavi 2018; Ricciuto et al. 2018; Sarrazin et al. 2016; Zadeh et al. 2017) and land-surface models (Bastidas et al. 2006; Liu et al. 2004; Santanello Jr et al. 2011; Xiong et al. 2010), numerical weather prediction (NWP) models ( $\mathrm{Di}$ et al. 2015; Johannesson et al. 2014; Quan et al. 2016), and climate models (Edwards and Marsh 2005; Fanning and Weaver 1997; Murphy et al. 2004; Neelin et al. 2010).

We intend to employ SA methods to identify the most sensitive parameters that have significant influences on 
the simulation of interested climatic variables such as surface air temperature, global water budget components including precipitation, evaporation over land and ocean, and runoff over land simulated. Here, we chose an EMIC named LOVECLIM as an example to illustrate the effectiveness of SA methods. Then we evaluated the perturbed parameters and find some individual parameter sets have better agreements to some aspects of selected climatic variables, implying that automatic parameter tuning has the potential to further improve the performance of LOVECLIM.

We choose to focus on sensitivity of parameter specification on the simulations of surface air temperature and global water balance components in this study because those climatic variables have the most direct impacts on human beings and on Earth's sustainability. Recent IPCC assessment reports suggested that current GCMs performed reasonably well in capturing the global mean temperature trend over the last 150 years. However, there was a persistent discrepancy between different GCMs in terms of global mean absolute temperature simulations, which differed by as much as $3{ }^{\circ} \mathrm{C}$ in both IPCC AR4 and IPCC AR5 (IPCC 2007; IPCC 2013; Mauritsen et al. 2012). All climate models are supposed to confirm to physical laws such as the conservation of mass and energy and water's freezing point always being $0{ }^{\circ} \mathrm{C}$ given Earth's condition. When the global mean temperature simulations differ by $3{ }^{\circ} \mathrm{C}$ or more, the following issues would arise. The involved models would contain very different land states (i.e., water may be in liquid state more likely in one model, while in frozen state in another) and this would ultimately affect the land hydrological processes. In addition, the land-atmosphere interactions would be very different, leading to different global water and energy budgets. Therefore, absolute global surface air temperature is an important metric for summarizing the state of the global climate (Hansen et al. 2006). Parameter specification can strongly affect the simulation of the hydrological cycle on Earth (Chahine 1992), which in turn influences Earth's simulated climate in a variety of ways. The exchanges of moisture and heat between the atmosphere and Earth's surface fundamentally affect the dynamics and thermodynamics of the climate system (Jones 2014). According to the ClausiusClapeyron relation, the specific humidity increases exponentially with temperature under a background of climate change (Allen and Ingram 2002). The ClausiusClapeyron relation states that the water-holding capacity of the atmosphere increases by approximately $7 \%$ for every $1{ }^{\circ} \mathrm{C}$ rise in temperature. Incorrect simulation of hydrological cycle would lead to incorrect simulation of extreme climatic events, such as extreme precipitation and drought. By choosing global mean absolute surface air temperature and global water budget components as the parameter optimization targets (Eyring et al. 2016; Mauritsen et al. 2012), we hope to achieve better simulated global climate patterns. This article includes five sections: Introduction gives the background to the research; Methods and tools introduces the sampling method, sensitivity analysis method, and tools used in this study; Model and parameters introduces the basic information for LOVECLIM and the adjustable parameter information; Results and discussion analyzes and discusses the experimental results; and Conclusions provides the summary and conclusions.

\section{Methods and tools}

The purpose of a sensitivity analysis (SA) is to quantify the influence of different parameters on the model outputs of interest. The SA process works as follows: (1) identify the adjustable parameters and their feasible ranges, (2) generate samples in high-dimensional parameter space and run the model with those samples, and (3) choose one or more appropriate SA methods and objective functions to quantify the parameter sensitivity with the input parameters and output variables. The adjustable parameters and their feasible ranges are presented in "Results and discussion" section. Below, we provide a brief description of the sampling method, SA method and tools used in this study.

\section{Sampling method}

In previous research (Gong et al. 2016a), we have found that the good lattice points (GLP) method can generate relatively more uniform samples than other methods, such as the widely used Monte Carlo and Latin Hypercube methods; therefore, we choose this sampling method in this study. The GLP method is also called the Korobov lattice rules (Hlawka 1962; Korobov 1959a; Korobov 1959b; Korobov 1960), which is a number theory-based quasi-Monte Carlo (QMC) method. The GLP design is generated by the following equations:

$$
\left\{\begin{array}{c}
q_{k i}=k h_{i}(\bmod n) \\
x_{k i}=\left(2 q_{k i}-1\right) / n
\end{array}, k=1, \cdots, n ; i=1, \cdots, s\right.
$$

where $n$ represents the number of samples, $s$ represents the number of dimensions, $x_{k i}$ represents the coordinate of the $k$ th sample point in the $i$ th dimension, $q_{k i}$ represents an internal variable, and $h_{i}$ represents an element in the generating vector. The range of coordinate $x_{k i}$ is restricted to $[0,1]$. The greatest common divisor of $h_{i}$ and $n$ is 1 . The vector $\left(n: h_{1}, \cdots, h_{s}\right)$ is called the generating vector. If the point set $P_{n}=\left\{x_{k}=\left(x_{k 1}, \cdots, x_{k s}\right), k=1\right.$, $\cdots, n\}$ is more uniform than any other generating vectors, then the point set $P_{n}$ is selected as the GLP set. With the uniformly scattered samples generated by the GLP method, we can cover the parameter space with 
less samples and, thus, save computational resource costs for the sensitivity analysis.

\section{Sensitivity analysis methods}

This study employed two qualitative SA methods to perform the parameter screening: multivariate adaptive regression splines (MARS) and random forests (RF). Moreover, to validate the parameter screening results obtained by the qualitative methods, the sparse polynomial chaos expansion (PCE)-based Sobol' method (SPC) was applied to compute the total effects of the parameters.

\section{Multivariate adaptive regression splines}

The MARS method (Friedman 1991) is a generalization of the stepwise linear regression, and it is suitable for high-dimensional problems. We call the two expanded piecewise linear basis functions $(x-t)_{+}$and $(t-x)_{+}$used in the MARS the reflected pair, where $t$ is a constant called the knot. Our aim is to form reflected pairs for each parameter $\mathrm{X}_{\mathbf{j}}$ with knots at each $x_{i j}$ value for that input. Therefore, the collection of basic functions is

$$
\begin{aligned}
\mathrm{C}= & \left\{\left(X_{j}-t\right)_{+},\left(t-X_{j}\right)_{+}\right\} \\
& \times\left(t \in\left\{x_{1 j}, x_{2 j}, \cdots, x_{N j}\right\}, j=1,2, \cdots, p\right)
\end{aligned}
$$

where $N$ represents the number of samples, $p$ represents the total number of adjustable parameters, and $X_{j}$ represents the $j$-th adjustable parameter.

The MARS method includes a forward procedure and backward procedure. First, we build a forward stepwise linear regression using the functions from the set $C$ and its products. Thus, the model has the form

$$
f(X)=\beta_{0}+\sum_{m=1}^{M} \beta_{m} h_{m}(X)
$$

where $\beta_{0}$ represents the intercept, $\beta_{m}$ represents the slope, and $f(X)$ corresponds to the predicted value of the observable variables (i.e., the output variables), such as temperature or precipitation. Both $\beta_{0}$ and $\beta_{m}$ are regression coefficients in the regression model, and their values are estimated by minimizing the residual sum-ofsquares. Each $h_{m}(X)$ is a function of $\mathrm{C}$ or a product of two or more similar functions, and $M$ represents the number of functions. Equation (3) is a regression model that can predict the value of the observable variable $y_{i}$ with the parameter value $X$.

This model typically overfits the data; therefore, a backward deletion procedure should be applied. The term whose removal causes the smallest increase in the residual squared error is deleted from the model at each stage to produce an estimated best model $\left(\widehat{f}_{\lambda}\right)$ for each size (number of terms) of $\lambda$. The MARS procedure uses generalized cross-validation (GCV) to estimate the optimal value of $\lambda$ :

$$
\operatorname{GCV}(\lambda)=\frac{\sum_{i=1}^{n}\left(y_{i}-\widehat{f}_{\lambda}\left(x_{i}\right)\right)^{2}}{(1-M(\lambda) / n)^{2}}
$$

where $n$ represents the number of observations, $y_{i}$ represents the $i$ th observation, $\widehat{f}_{\lambda}\left(x_{i}\right)$ represents the estimated value of $y_{i}$, and $M(\lambda)$ represents the number of effective parameters in the model.

The importance of the removed variable is measured by the increase in GCV values between the pruned model and overfitted model (Steinberg et al. 1999). The greater the increase in GCV is, the more important the removed variable.

The MARS method can also be used as a surrogatemodel. Shahsavani et al. (2010) showed that using the MARS surrogate model to replace the original dynamic model can provide acceptable estimates of the total sensitivity indices at much lower costs.

\section{Random forest}

The random forest (RF) is a very efficient and increasingly popular machine-learning algorithm for both classification and regression problems that was introduced by Breiman (2001). RFs are a substantial modification of bagging (Breiman 1996) that construct multiple trees (i.e., forests) using bootstrap sampling, and their decisions are averaged. The main difference between RFs and bagging is that a RF searches a randomized subset of input variables to determine a split at each node, which is the reason why it is called "random" forests. The basic principle of RFs is a group of weak learners that can come together to form a strong learner.

The random forest algorithm is as follows:

1. Extract a bootstrap sample, $Z^{*}$, of size $N$ from the training data.

2. For each of the bootstrap samples, grow a random forest tree by recursively repeating the following steps ((a) to (c)) for each terminal node of the tree until the minimum node size $n_{\min }$ is reached.

(a) Randomly select $m$ variables from the total $\mathrm{p}$ variables, where $m<<p$.

(b) Among the $m$ variables, pick up the best variable/split point.

(c) Split the node into two daughter nodes using the best split.

3. Predict the new data by aggregating the predictions of the $N$ trees.

Compared with other classification and regression techniques, the RF has its unique advantages: RFs can 
avoid overfitting because of the law of large numbers, and RFs can be used to identify important factors. The total number of splits can determine the importance of this variable. The more splits the variable has, the more sensitive the variable is.

\section{Sparse PCE-based Sobol' method}

The Sobol' method (Sobol' 1993) is a quantitative SA method based on the principle of variance decomposition and can be applied to nonlinear, nonmonotonic mathematical models. Its core idea is to decompose the total variance of the objective function into the variance of a single parameter and the variance of the interaction between parameters. By comparing the three methods of PEST, RSA, and ANOVA with the Sobol' method, Tang et al. (2006) considered that the Sobol' method is more robust and superior to other methods in both single objective and multi-objective sensitivity analyses.

Suppose the problem can be considered as $y=f(X)=$ $f\left(X_{1}, \cdots, X_{k}\right)$, where $y$ represents the objective function of the model output (e.g., the root mean square errors of the simulated values and default values), and $X=\left(X_{1}, \cdots\right.$, $X_{k}$ ) is the vector of the $k$ model factors (e.g., parameters) to be used to control the behavior of the model. Without loss of generality, each parameter $X_{i}$ was supposed to be feasible in range $[0,1]$. Our purpose is to explore how much of the total variance $D(y)$ in $y$ can be explained by variability in the factors of $X$. The Sobol' method computes this by decomposing the function $f(X)$ into terms of increasing dimensionality, such that each successive dimension represents how much the interaction between parameters increases.

$$
\begin{aligned}
f\left(X_{1}, X_{2}, \cdots X_{k}\right)= & f_{0}+\sum_{i=1}^{k} f_{i}\left(X_{i}\right) \\
& +\sum_{1 \leq i<j \leq k} f_{i j}\left(X_{i}, X_{j}\right)+\cdots \\
& +f_{1,2, \cdots, k}\left(X_{1}, \cdots, X_{k}\right)
\end{aligned}
$$

where $f_{0}$ is constant that equals to the expected value of $f(X), f_{i}\left(X_{i}\right)$ is a function of the $i$ th parameter, $f_{i j}\left(X_{i}, X_{j}\right)$ is a function of the $i$ th and $j$ th parameters, etc. The integrals of the decomposed functions (also called summands) $f_{i}\left(X_{i}\right), f_{i j}\left(X_{i}, X_{j}\right), \cdots, f_{1,2}, \cdots, k\left(X_{1}, \cdots, X_{k}\right)$ are equal to zero:

$$
\int_{0}^{1} f_{i_{1}, i_{2}, \cdots, i_{s}}\left(X_{i_{1}}, \cdots, X_{i_{s}}\right) d x_{i_{k}}=0 \text { if } 1 \leq k \leq s
$$

All the summands can be computed recursively like this:

$$
\begin{gathered}
f_{0}=\int_{0}^{1} \ldots \int_{0}^{1} f(\boldsymbol{X}) d \boldsymbol{X}, \\
f_{i}\left(X_{i}\right)=\int_{0}^{1} \ldots \int_{0}^{1} f(\boldsymbol{X}) d \boldsymbol{X}_{\sim i}-f_{0}, \\
f_{i j}\left(X_{i}, X_{j}\right)=\int_{0}^{1} \ldots \int_{0}^{1} f(\boldsymbol{X}) d \boldsymbol{X}_{\sim i j}-f_{0}-f_{i}\left(X_{i}\right)-f_{j}\left(X_{j}\right),
\end{gathered}
$$

The notation $\sim$ means the parameters are excluded like this $X_{\sim i}=\left(X_{1}, \ldots, X_{i-1}, X_{i+1}, \ldots, X_{k}\right)$.

The total variance of the function $f(X)$ is defined as:

$$
D(Y)=\int_{0}^{1} \cdots \int_{0}^{1} f^{2}(\boldsymbol{X}) d \boldsymbol{X}-f_{0}^{2}
$$

And the contribution of a generic term $f_{i_{1}, \cdots, i_{s}}\left(1 \leq i_{1}\right.$ $\left.<\cdots<i_{s} \leq k\right)$ to the total variance can be written as

$$
D_{i_{1}, \cdots, i_{s}}=\int_{0}^{1} \cdots \int_{0}^{1} f_{i_{1}, \cdots, i_{s}}^{2}\left(X_{i_{1}}, \cdots, X_{i_{s}}\right) d X_{i_{1}} \cdots d X_{i_{s}}
$$

where $D_{i_{1}, \cdots, i_{s}}$ denotes the partial variance corresponding to $\left(i_{1}, \cdots, i_{s}\right)$, the integer $s$ is called the order or the dimension of the index. On this basis, the total variance of the output variable $Y$ can be decomposed into of all partial variances:

$$
D(y)=\sum_{i=1}^{k} D_{i}+\sum_{1 \leq i<j \leq k} D_{i j}+\cdots D_{1,2, \cdots k}
$$

where $D_{i}$ represents the contribution of factor $X_{i}$ to $D(y)$ and $D_{i j}$ represents the contribution of the interaction between factors $X_{i}$ and $X_{j}$. Similarly, $D_{1,2}, \ldots k$ represents the contribution by the interaction of $\mathrm{k}$ factors. The Sobol' sensitivity index of $\mathrm{s}$ factors is defined as

$$
S_{i_{1}, \cdots, i_{s}}=\frac{D_{i_{1}, \cdots i_{s}}}{D(Y)}, 1 \leq i_{1}<\cdots<i_{s} \leq k
$$

and the sum of all Sobol' sensitivity indices equals to 1 :

$$
1=\sum_{i=1}^{n} S_{i}+\sum_{1 \leq i<j \leq k} S_{i j}+\cdots+S_{1,2, \cdots, k}
$$

In the Sobol' method, $S_{i}=D_{i} / D(Y)$ is the main effect (i.e., the first-order effect) of the $i$ th variable, and $S_{i j}=$ $D_{i j} / D(Y)$ is the interaction effect (i.e., second-order effect) of the $i$ th and $j$ th variables. $S_{T i}=1-D_{\sim i} / D(Y)$ represents the total sensitivity of the $i$ th variable, where $D_{\sim i}$ represents total variance excluding the $i$ th variable.

Total effect reflects the parameter's overall contribution to the total variance. The total effect of a factor $X_{i}$ 
is the sum of the first-order effect (main effect) and all other order effects involving $X_{i}$, including two factor interaction effects and all higher order interaction effects.

Traditionally, the Sobol' indices are evaluated with Monte Carlo sampling, and to obtain an accurate estimation the number of sample size (equals to number of model simulation) is usually very high. Sobol' method is too expensive for computationally expensive models. Using surrogate model to replace the expensive dynamic model in Sobol' method can significantly save the computational resources. Sudret (2008) proposed a post-processing of polynomial chaos expansions (PCE) that can directly obtain the Sobol' sensitivity indices from the polynomial coefficients of PCE. Comparing with the Monte Carlo sampling and the PCE-based way of computing Sobol' indices, Sudret's PCE-based method cost less computational resources and can obtain more accurate result.

Here is a brief introduction to sparse PCE Sobol' method. Considering a random vector with independent components $X \in \mathbb{R}^{k}$ and a computational model $Y=f(X)$ with finite variance, the polynomial chaos expansion of $f(X)$ is defined as:

$$
Y=f(\boldsymbol{X})=\sum_{\boldsymbol{\alpha} \in N^{k}} \lambda_{\boldsymbol{\alpha}} \Psi_{\boldsymbol{\alpha}}(\boldsymbol{X})
$$

where the $\Psi_{\boldsymbol{\alpha}}(\boldsymbol{X})$ are multivariate polynomials orthonormal with respect to the distribution of $X, \boldsymbol{\alpha} \in \mathbb{N}^{k}$ is a vector of indices that identifies the components of the multivariate polynomials $\Psi_{\boldsymbol{\alpha}}$, and the corresponding $\lambda_{\boldsymbol{\alpha}} \in$ $\mathbb{R}$ are the coefficients of each orthonormal. Equation (13) is usually referred to as the polynomial chaos expansion (PCE) of $Y$. In realistic applications, the truncated polynomial chaos expansions are usually introduced to retain only a finite number of PCE terms:

$$
f(\boldsymbol{X}) \approx f^{P C}(\boldsymbol{X})=\sum_{\boldsymbol{\alpha} \in \mathcal{A}} \lambda_{\boldsymbol{\alpha}} \Psi_{\boldsymbol{\alpha}}(\boldsymbol{X})
$$

In this equation, $\mathcal{A}$ is the set of vectors of selected indices of multivariate polynomials. This equation is called the full polynomial chaos. The key of constricting a sparse polynomial chaos (SPC) is to determine the coefficients $\lambda_{\boldsymbol{\alpha}}$ of each term. In this paper, we used the orthogonal matching pursuit (OMP) originally proposed by Pati et al. (1993) to determine the polynomial coefficients.

The Sobol' indices can be computed from the polynomial coefficients $\lambda_{\alpha}$ directly as follows:

$$
\begin{aligned}
& E(f(\boldsymbol{X})) \approx \lambda_{0}, \\
& V(f(\boldsymbol{X})) \approx \sum_{\alpha \in A} \lambda_{\boldsymbol{\alpha}}^{2}, \\
& S_{i} \approx \frac{1}{V(f(\boldsymbol{X}))} \sum_{\boldsymbol{\alpha} \in \mathcal{A}_{S_{i}}} \lambda_{\boldsymbol{\alpha}}^{2} \text { with } \mathcal{A}_{S_{i}}=\left\{\boldsymbol{\alpha}: \alpha_{i}>0, \alpha_{k}=0 \text { for } k \neq i\right\}, \\
& S_{T i} \approx \frac{1}{V(f(\boldsymbol{X}))} \sum_{\boldsymbol{\alpha} \in \mathcal{A}_{S_{T i}}} \lambda_{\boldsymbol{\alpha}}^{2} \text { with } \mathcal{A}_{S_{T i}}=\left\{\boldsymbol{\alpha}: \alpha_{i}>0\right\},
\end{aligned}
$$

where $\mathcal{A}_{S_{i}}$ is the set of indices vectors that only have the $i$ th factor, while $\mathcal{A}_{S_{T i}}$ is the set of indices vectors that have the $i$ th factor and maybe also others, $E(f(X))$ and $V(f(\boldsymbol{X}))$ are mean and variance of $f(\boldsymbol{X})$, respectively. The confidence intervals of Sobol' sensitivity indices can be estimated with the bootstrap method (Efron 1979).

\section{Tools}

The Uncertainty Quantification Python Laboratory (UQPyL) (Wang et al. 2016) is a flexible software platform designed to quantify uncertainties in large complex dynamical models. UQ-PyL integrates different kinds of UQ methods, including experimental design, statistical analysis, sensitivity analysis, surrogate modeling, and parameter optimization. In this study, we used the unreleased developed version of the UQ-PyL for the experimental design and sensitivity analysis. The MARS algorithm is available from the open-source software pyearth (https://github.com/scikit-learn-contrib/py-earth), the Sobol' method implemented in SALib (https:// github.com/SALib/SALib), and the Sparse PCE-based Sobol' method we used comes from UQLab (https:// www.uqlab.com/).

\section{Model and parameters}

We selected an EMIC called LOVECLIM (Goosse et al. 2010) to explore the parameter sensitivity of its various output variables. LOVECLIM has five components: the atmospheric model ECBILT (Opsteegh et al. 1998), the sea-ice and ocean model CLIO (Goosse and Fichefet 1999), the terrestrial biosphere model VECODE (Brovkin et al. 1997), the ocean carbon-cycle model LOCH (Mouchet and François 1996), and the ice-sheet model AGISM (Huybrechts 2002). Originally, the ECBILT and CLIO were coupled in the late 1990s (Goosse et al. 2001; Goosse et al. 2002). This version is followed by the ECBILT-CLIO-VECODE model, which includes the terrestrial biosphere (Renssen et al. 2003; Renssen et al. 2005). The LOVECLIM acronym (LOCH-VECODEECBILT-CLIO-AGISM) has been used when the LOCH and AGISM models were part of the system. In this study, we used LOVECLIM version 1.3 and only coupled the ECBILT-CLIO-VECODE components. The LOCH and AGISM components were not utilized in this article 
because they are not necessary for the processes investigated here, they are not public, and their use is subject to permission.

Loutre et al. (2011) and Goosse et al. (2007) explored the impact of parameter changes on the performance of the LOVECLIM with various parameter sets. Based on their experience on selecting adjustable parameters and the physical meanings of the parameters, 25 parameters in LOVECLIM are chosen as the adjustable parameters in this study. Previous studies have shown that approximately $\pm 30 \%$ perturbations in the default parameter values were suggested for the sensitivity and uncertainty analyses (Tan et al. 2017). One way to make the reduction of model large-scale biases and the parameterization development processes more "in tune" is by deriving an acceptable range of parameter values instead of a single value from the aforementioned process studies and use this range when tuning global simulations (Hourdin et al. 2017). Based on our experience and the physical meanings of the adjustable parameters, we determined the feasible ranges of the parameters, as shown in Table 1. These adjustable parameters can be classified into three categories: atmosphere, land, and ocean. A rough rule of thumb about the sample size is that at least $10 \times n$ sample points are needed to identify the key factors (i.e., parameters), where $n$ represents the number of experimental factors (Levy and Steinberg 2010). In this study, $25 \times 10=250$ samples were generated with the GLP method.

\section{Results and discussion}

\section{Experiment on the perturbed parameters}

We performed climate simulations using LOVECLIM over a 2100 -year period from 1 to 2100 C.E. using the default model parameters as treat the simulation as control run. We then run LOVECLIM model 250 times using sampled parameter sets generated by the GLP method described in "Methods and tools" section for the same period. We chose six output variables as the analysis objects: global mean near-surface air temperature $\left(T_{\mathrm{G}}\right)$, total global runoff over land surface $\left(R_{\mathrm{L}}\right)$, total precipitation over land surface and ocean $\left(P_{\mathrm{L}}\right.$ and $\left.P_{\mathrm{O}}\right)$, and total evaporation over land surface and ocean $\left(E_{\mathrm{L}}\right.$ and $E_{\mathrm{O}}$ ).

According to the analysis of these output variables, we found that 189 simulation results are valid, while the other simulations drifted or crashed during the simulation period. We have also examined the trends of $T_{\mathrm{G}}$ in these 189 simulations over the period 1001 to 1800 C.E., the maximum absolute value of the trends is $0.00291{ }^{\circ} \mathrm{C} /$ year, which is within a reasonable range. Figure 1 shows all of the time series of the output variables simulated with perturbed parameters, with the redline denoting the climatological means of observations and the black line denoting the ensemble mean. The climatological means of observations of $T_{\mathrm{G}}$ used is the twentiethcentury average provided by NOAA (https://www.ncdc. noaa.gov/sotc/global/201613), and the global water budget components $R_{\mathrm{L}}, P_{\mathrm{L}}, P_{\mathrm{O}}, E_{\mathrm{L}}$, and $E_{\mathrm{O}}$ is obtained from the work by Trenberth et al. (2007) based on ERA40 reanalysis data. Their ensemble spreads span across a wide range, and the differences between the highest values and lowest values are significant. From Fig. 1a-f, the maximum ranges between the highest values and lowest values are $10.35{ }^{\circ} \mathrm{C}, 22.16 \times 10^{3} \mathrm{~km}^{3}, 88.67 \times$ $10^{3} \mathrm{~km}^{3}, \quad 264.82 \times 10^{3} \mathrm{~km}^{3}, \quad 84.17 \times 10^{3} \mathrm{~km}^{3}$, and $269.61 \times 10^{3} \mathrm{~km}^{3}$, respectively. Note that the ensemble spreads of some variables covered the climatological values, including $T_{\mathrm{G}}, P_{\mathrm{L}}, P_{\mathrm{O}}, E_{\mathrm{L}}$, and $\mathrm{E}_{\mathrm{O}}$. However, the observed climatological mean of $R_{\mathrm{L}}$ is out of the range of the ensemble spread, indicating a model structural problem, which will be elaborated more in details later.

Figure 2 shows the probability density function for the results of the output variables using perturbed parameters and compares them with the simulation results using the default parameter and climatological mean values. Compared with the climatological mean, the simulation with default parameters has a warming bias of approximately $1{ }^{\circ} \mathrm{C}$, and $P_{\mathrm{L}}, P_{\mathrm{O}}, E_{\mathrm{L}}$, and $E_{\mathrm{O}}$ are all positively biased, indicating a more active hydrological cycle than observed occurred. Compared with the ERA40 reanalysis data, $R_{\mathrm{L}}$ has a significant negative bias and $E_{\mathrm{L}}$ has a strong overestimation. Comparing with the real world, the runoff over land surface is too little, while evapotranspiration over land is too much. The positively biased $E_{\mathrm{L}}$ leads to biased surface latent heat flux and may possibly have some influence of global energy balance.

The entire simulated hydrological processes in LOVECLIM seem to be significantly biased. Taking the control run with default parameters as an example, almost all of the precipitation over land was evaporated. As shown in Fig. $2 \mathrm{~b}$, the error in $R_{\mathrm{L}}$ was as large as $16.28 \times 10^{3} \mathrm{~km}^{3}$, equals to $40.7 \%$ of the $40 \times 10^{3} \mathrm{~km}^{3}$ total global runoff. Furthermore, none of the perturbed parameter sets can simulate large enough runoff values. It might be very difficult to find a parameter that can correct the bias of runoff without degrading other processes. This result invoked us to think about the problem of the model structure. According to Goosse et al. (2010), a very simple LBM (land-surface bucket model) is used to describe hydrological processes. The LBM has a bucket scheme, whose bottom has no water leakage. The only way to generate runoff is to fill up the bucket. This might be a possible reason for the negatively biased runoff. In the real world, part of the soil water stored in deep layers does not take part in evapotranspiration; it becomes runoff if the deep soil is saturated while the topsoil is 
Table 1 List of selesscted adjustable parameters and their ranges of LOVECLIM

\begin{tabular}{|c|c|c|c|c|c|c|c|c|c|c|c|}
\hline & \\
\hline Index & Module & Parameter & Definition & Default & Range & Index & Module & Parameter & Definition & Default & Range \\
\hline \multirow[t]{2}{*}{ P1 } & \multirow[t]{2}{*}{$\begin{array}{l}\text { ECBILT- } \\
\mathrm{atm}\end{array}$} & \multirow[t]{2}{*}{ ampwir } & \multirow{2}{*}{$\begin{array}{l}\text { Scaling coefficient for the } \\
\text { longwave radiation } \\
\text { scheme } \\
\text { (amplw)_general value } \\
\text { (excluding the equator } \\
\text { area). }\end{array}$} & \multirow[t]{2}{*}{1} & \multirow[t]{2}{*}{$\begin{array}{l}{[0.5,} \\
1.5]\end{array}$} & $\overline{\mathrm{P} 20}$ & $\begin{array}{l}\text { ECBILT- } \\
\text { land }\end{array}$ & bmoismfix & $\begin{array}{l}\text { Maximum bucket depth } \\
\text { (unit: } \mathrm{m} \text { ) }\end{array}$ & 0.15 & $\begin{array}{l}{[0.01} \\
0.50]\end{array}$ \\
\hline & & & & & & P21 & $\begin{array}{l}\text { CLIO- } \\
\text { ocean }\end{array}$ & bering & $\begin{array}{l}\text { Scaling factor for } \\
\text { computing the Bering } \\
\text { Strait throughflow }\end{array}$ & 0.3 & $\begin{array}{l}{[0.2,} \\
0.5]\end{array}$ \\
\hline \multirow[t]{2}{*}{ P2 } & \multirow{2}{*}{$\begin{array}{l}\text { ECBILT- } \\
\mathrm{atm}\end{array}$} & \multirow[t]{2}{*}{ ampeqir } & \multirow{2}{*}{$\begin{array}{l}\text { Scaling coefficient for the } \\
\text { longwave radiation } \\
\text { scheme (amplw)-for the } \\
\text { equator area between } \\
15^{\circ} \mathrm{S} \text { and } 15^{\circ} \mathrm{N} \text {. }\end{array}$} & \multirow[t]{2}{*}{1.8} & \multirow{2}{*}{$\begin{array}{l}{[1.0,} \\
2.5]\end{array}$} & P22 & $\begin{array}{l}\text { CLIO- } \\
\text { ocean }\end{array}$ & ai & $\begin{array}{l}\text { Coefficient of isopycnal } \\
\text { diffusion (unit: } \mathrm{m}^{2} \mathrm{~s}^{-1} \text { ) }\end{array}$ & 300 & $\begin{array}{l}{[200,} \\
400]\end{array}$ \\
\hline & & & & & & P23 & $\begin{array}{l}\text { CLIO- } \\
\text { ocean }\end{array}$ & aitd & $\begin{array}{l}\text { Gent-McWilliams } \\
\text { thickness diffusion } \\
\text { coefficient (unit: } \mathrm{m}^{2} \mathrm{~s}^{-1} \text { ) }\end{array}$ & 300 & $\begin{array}{l}{[200,} \\
400]\end{array}$ \\
\hline \multirow[t]{2}{*}{ P3 } & \multirow[t]{2}{*}{$\begin{array}{l}\text { ECBILT- } \\
\text { atm }\end{array}$} & \multirow[t]{2}{*}{ expir } & \multirow{2}{*}{$\begin{array}{l}\text { Exponent for the } \\
\text { longwave radiation } \\
\text { scheme }\end{array}$} & \multirow[t]{2}{*}{0.4} & \multirow[t]{2}{*}{$\begin{array}{l}{[0.2,} \\
0.6]\end{array}$} & P24 & $\begin{array}{l}\text { CLIO- } \\
\text { ocean }\end{array}$ & ahs & $\begin{array}{l}\text { Horizontal diffusivity for } \\
\text { scalars (unit: } \mathrm{m}^{2} \mathrm{~s}^{-1} \text { ) }\end{array}$ & 100 & $\begin{array}{l}{[50} \\
150]\end{array}$ \\
\hline & & & & & & P25 & CLIO- & ahu & Horizontal viscosity (unit: & 1E5 & {$[0.5 \mathrm{E}$} \\
\hline P4 & $\begin{array}{l}\text { ECBILT- } \\
\text { atm }\end{array}$ & relhmax & $\begin{array}{l}\text { Precipitation also occurs } \\
\text { if the total precipitable }\end{array}$ & 0.83 & $\begin{array}{l}{[0.50} \\
0.90]\end{array}$ & & & & & & \\
\hline
\end{tabular}

unsaturated. Consequently, in hydrological models, usually a leaky bucket (or multiple leaky buckets) are used to describe this process. If the bucket is not leaky, all of the water must take part in evapotranspiration, similar to a "shallow sea" scenario, and runoff cannot be generated from half-filled bucket. The oversimplified LBM model may lead to negatively biased runoff, overestimated evapotranspiration and latent heat flux over land, and biased thermodynamic discrepancy between land and ocean. Too much water involved in land evapotranspiration may possibly be the reason why the simulated global hydrological cycle is stronger than that of the real world, as it pumps more water into the atmosphere. Because of the complex interactions among the atmosphere, land, sea, and biosphere, the influence of a biased hydrological process may distort the global climate and lead to biased future climate projections.

\section{The overall sensitivity analysis results}

The simulation results of year 1951 to 2000 C.E. were selected for sensitivity analysis. Figure 3 shows the SA results for three output variables: global mean surface temperature, total global precipitation, and total global evaporation with three SA methods: the MARS, random forest, and sparse PCE-based Sobol' methods (SPC). The sensitivity scores of the 25 parameters are normalized to $[0,1]$. The blue columns in the figures represent the SA results (MARS GCV score) of the MARS method; the red columns in subfigures (a) (c) (e) represent the SA results (RF score) of the random forests, while the red columns in subfigures (b) (d) (f) represent the SA results (Sobol' indices) of the SPC method. As shown in Fig. 3a, $\mathrm{b}$, the parameters $\mathrm{P} 1, \mathrm{P} 3$, and $\mathrm{P} 4$ are very sensitive to surface temperature with the three SA methods, while the other parameters are not sensitive to surface temperature within the adjustable range of parameters we chose in this study. For the total global precipitation 



Fig. 1 The time series of output variables simulated with default and perturbed parameters. a Global mean near-surface air temperature $\left(T_{\mathrm{G}}\right)$. b Total global runoff over land surface $\left(R_{\mathrm{L}}\right)$. c Precipitation over land surface $\left(P_{\mathrm{L}}\right)$. d Precipitation over ocean $\left(P_{\mathrm{O}}\right)$. e Evapotranspiration over land surface $\left(E_{\mathrm{L}}\right)$. $\mathbf{f}$ Evaporation over ocean $\left(E_{\mathrm{O}}\right)$

and total evaporation, the results of the MARS, RF, and SPC methods are consistent with each other, and the parameters P1, P2, P3, P4, P6, and P19 are sensitive. The confidence intervals of Sobol' indices have also been estimated with bootstrap method. The $25 \%$ and $75 \%$ quantiles of each indices were shown in Fig. 3b, d, f. Comparing with the magnitude of Sobol' indices, the range of confidence intervals are relatively small, leading to a high confidence of the result of sensitivity analysis. Although there are some discrepancies in the order of sensitivity scores, three different methods have reached a consensus that which parameters are sensitive and which are not. In general, we can conclude that the three methods produce similar results with satisfying confidence to make a solid conclusion.

Furthermore, we have also evaluated the parameter sensitivity of pre-industrial age (1701 to 1800 C.E.). Generally speaking, the sensitivity analysis results are similar to that of current age (1951 to 2000 C.E.). All of the figures presenting sensitivity analysis results of both periods can be found in the Additional file 1: Figures S1S12. In the following parts of this paper, only results of current age (1951 to 2000 C.E.) were presented. 

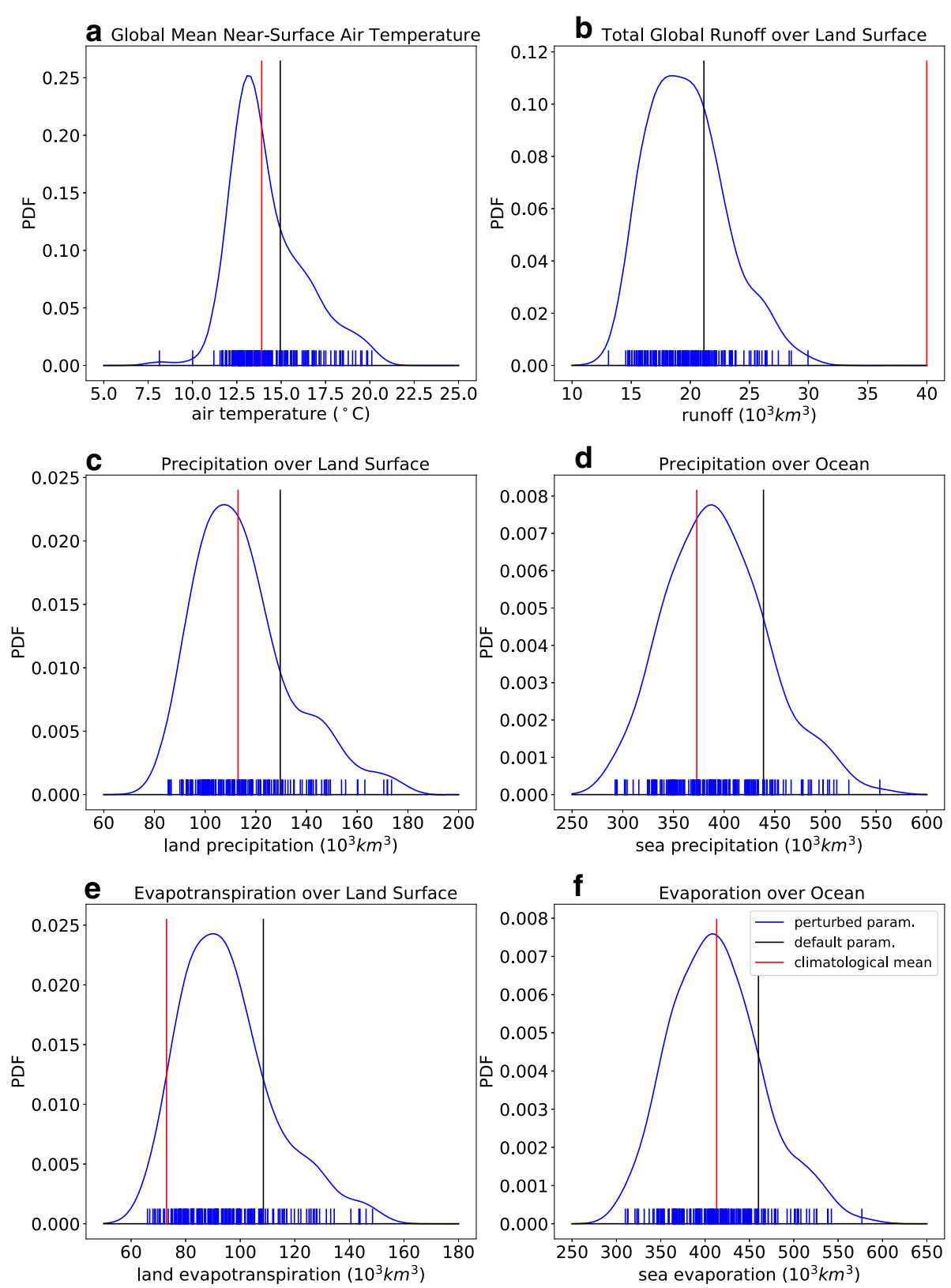

Fig. 2 The probability density function (PDF) of the simulation with perturbed parameters, simulation with default parameters and the climatological mean data. a Global mean near-surface air temperature $\left(T_{G}\right)$. b Total global runoff over land surface $\left(R_{\downarrow}\right)$. c Precipitation over land surface $\left(P_{\downarrow}\right)$. d Precipitation over ocean $\left(P_{\mathrm{O}}\right)$. e Evapotranspiration over land surface $\left(E_{\mathrm{L}}\right)$. $\mathbf{f}$ Evaporation over ocean $\left(E_{\mathrm{O}}\right)$

\section{Sensitivity analysis results of global mean output variables}

Figure 4 shows the sensitivity results of the global mean values of 20 output variables (Table 2) to 25 adjustable parameters provided by the SPC method. We find that parameters P1, P3, P4, and P19 are sensitive for almost every variable. Parameters P2, P5, P6, and P9 are sensitive for 8-15 variables. All other parameters are slightly sensitive for the selected output variables.
Referring to the parameter list in Table 1, we find that the sensitive parameter P1 and P2 are scaling coefficient for the longwave radiation scheme, which controls the radiation due to the anomaly of humidity. The parameter P3 is the exponent of humidity anomaly for the longwave radiation scheme. The sensitivity of the above three parameters confirms our prior knowledge that the longwave radiation from atmospheric water vapor is an important factor in the global climate system. The P4 parameter, which is about microphysics and 

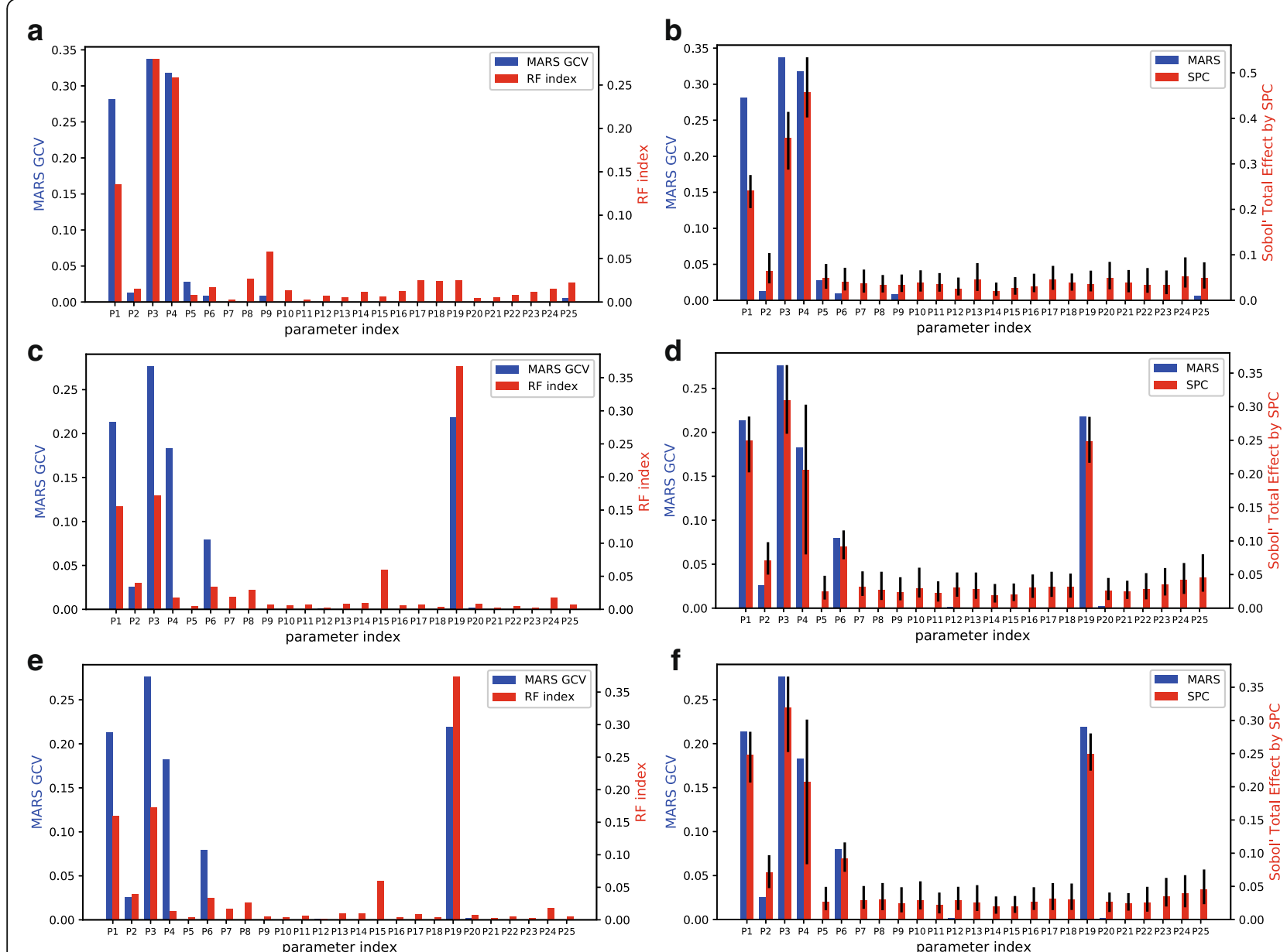

Fig. 3 SA results of the three variables with the MARS, random forests, and SPC methods. a Sensitivity scores for the global mean surface temperature via MARS and the RF. $\mathbf{b}$ Sensitivity scores for the global mean surface temperature via the MARS and SPC methods. c Sensitivity scores for total global precipitation via MARS and the RF. $\mathbf{d}$ Sensitivity scores for total global precipitation via the MARS and SPC methods. e Sensitivity scores for total global evaporation via MARS and the RF. $\mathbf{f}$ Sensitivity scores for total global evaporation via the MARS and Sobol' methods

precipitation, can also influence many aspects of global climate. As the only global microphysics parameter, P4 controls the amount of atmospheric water vapor and precipitation worldwide, and consequently influence the global energy balance. The drag coefficients P5 (for wind stress) and P6 (for sensible and latent heat fluxes) are also important because they played an important role in land-atmosphere interactions. P6 is more important because the sensible and latent heat flux can influence both energy and water balance. The parameters P1 to P6 are about global water and energy balance in the atmosphere module, and we have confirmed that they have strong influence to the global climate simulation. The snow albedo P9 can influence radiation and temperature terms, confirming that the parameterization of snow cover is important for climate modeling. The maximum evaporation factor over land (P19), which can adjust the evapotranspiration amount over land surface, is also sensitive to many output variables, indicating the importance of land surface evapotranspiration process to the global climate system.

However, some parameters that are considered to be also important, or at least functional, were shown to be only slightly sensitive in our results. The snow/ice parameters such as the albedos of bare ice (P10), melting snow (P11), melting ice (P12, P13, P14) and correct factor of snow/ice albedo under cloudy conditions (P15), the precipitation and microphysics regional reduction factors P16 P18, and all of the ocean module parameters P21 P25. The most unexpected result is that all of the ocean parameters are only a little sensitive in the time scale of thousands of years, which somehow disagree with our prior knowledge that the ocean processes controls the climate variability in the time scale of hundreds to thousands of years. All of the three sensitivity analysis methods, namely MARS, RF, and SPC, have reached a consensus that the ocean parameters are at least not relatively important in the range evaluated in 


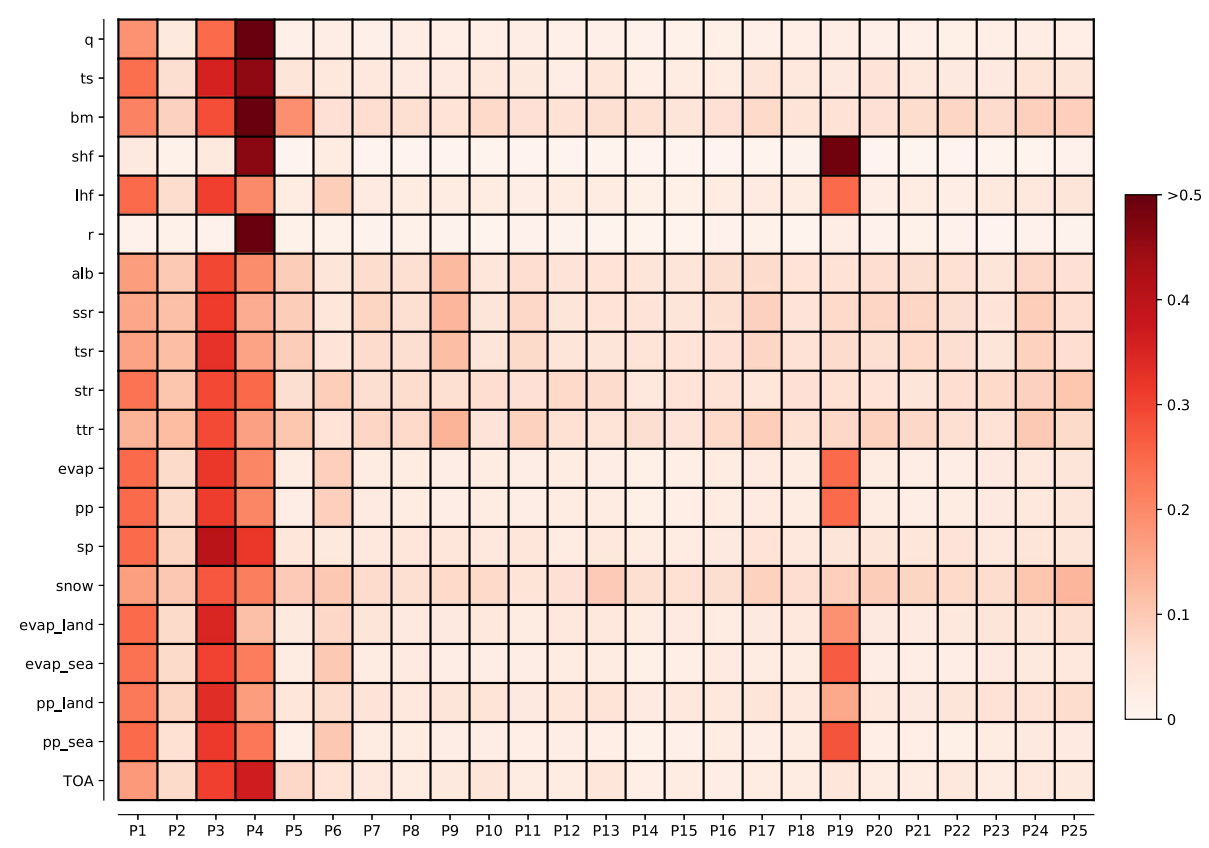

Fig. 4 Sobol' sensitivity index of global mean output variables ( $x$-axis) to the 25 adjustable parameters ( $y$-axis)

Table 2 Output variables of LOVECLIM

\begin{tabular}{lll}
\hline No. & Name & Definition \\
\hline 1 & q & Specific humidity \\
2 & ts & Surface temperature \\
3 & bm & Bottom moisture \\
4 & shf & Surface sensible heat flux \\
5 & Ihf & Surface latent heat flux \\
6 & r & Relative humidity \\
7 & alb & Surface albedo \\
8 & ssr & Surface solar radiation \\
9 & tsr & Top solar radiation \\
10 & str & Surface thermal radiation \\
11 & ttr & Top thermal radiation \\
12 & evap & Surface evaporation \\
13 & pp & Total precipitation \\
14 & sp & Surface pressure \\
15 & snow & Total snow fall \\
16 & evap_land & Surface evaporation over land \\
17 & evap_sea & Surface evaporation over sea \\
18 & pp_land & Total precipitation over land \\
19 & TOA & Total precipitation over sea \\
20 & & Top of the atmosphere net flux \\
\hline &
\end{tabular}

this research. Furthermore, the confidence interval estimated with SPC made this conclusion more solid.

To further confirm this conclusion, we have also evaluated the interaction effects with SPC method. The results have been shown in Additional file 1: Figures S3 and S4. Both the mean value and the standard deviation of Sobol' indices were presented. The results indicated that only a few interactions are significant, and most others, such as the ocean module parameters P21 P25, do not have strong interactions. The standard deviation represented the uncertainty, or the confidence of Sobol' indices estimation. Generally speaking, the uncertainty of interaction estimation is relatively not large, confirming that the estimation of interaction effects is accurate enough to make a solid conclusion.

To sum up, considering the parameterization scheme and the implemented physics of LOVECLIM, some parameters in this model are really not strongly sensitive to the listed model output variables, yet they might be sensitive to some variables not involved in this study, such as the meridional overturning circulation (MOC). Further investigation with more recent advanced sensitivity analysis methods and involving more simulated processes may lead to deeper understanding about the model behavior and the deep interactions between atmosphere, land, ocean and cryosphere.

\section{Spatial dependence of sensitivity results}

Figure 5 shows the MARS GCV of the grid mean values of surface air temperature to 25 adjustable parameters. This figure presents the spatial distribution of the 


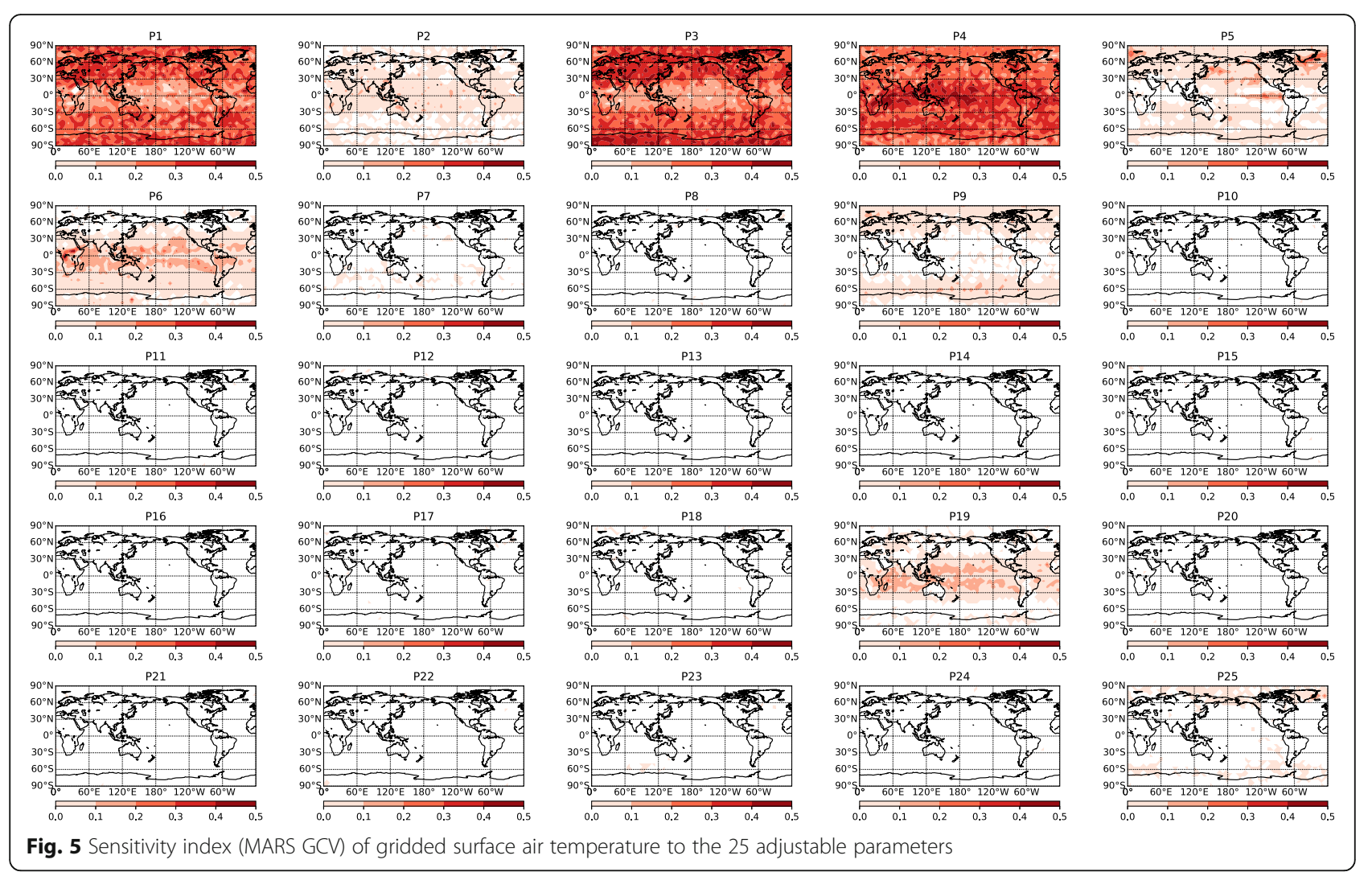

sensitivity index MARS GCV of surface air temperature, indicating the diversity of sensitivity index between land/sea surfaces and between different latitudes. Generally, there are nine parameters that are globally sensitive regarding surface temperature. Among them, P1, P3, and P4 are the most sensitive parameters for surface temperature. P1 and P3 are more sensitive in mid- and high-latitude regions, while $\mathrm{P} 4$ is more sensitive in tropical regions. The sensitivities of $\mathrm{P} 1, \mathrm{P} 3$, and $\mathrm{P} 4$ do not have significant land/sea differences. P2, P5, P6, P9, P19, and P25 are marginally sensitive and have some latitudinal discrepancies. Other parameters are nearly insensitive for every variable.

In Fig. 6, parameters P1, P3, P4, P5, and P19 are the most sensitive parameters, while P2, P6, P9, and P25 are marginally sensitive for the global grid mean values of precipitation. P5 is very sensitive in the tropical Pacific region, while $\mathrm{P} 1$ and $\mathrm{P} 3$ are not sensitive in this region. P4 has several sensitive regions west of the continents. $\mathrm{P} 19$, as a maximum evaporation factor over land, is significantly sensitive globally over both land and sea.

In Fig. 7, parameters P1, P3, and P19 are the parameters that are most sensitive to evaporation, while P2, P4, P5, P6, P9, and P25 are marginally sensitive. P2 is sensitive in the tropical region, and P5 is sensitive in the tropical Pacific.
Figures 5, 6, and 7 also show the spatial distributions of the parameter sensitivities. Generally, parameters related to longwave radiation have a greater impact in mid- and high-latitude regions, while parameters related to microphysics and the land-surface evapotranspiration factor have a greater impact on low latitudes. Upon a comparison with Fig. 4, we find that the sensitivity parameters are almost the same for both the grid mean values of the variables and the global mean values.

\section{Potentials for improving climate simulations using perturbed parameters}

To verify the usefulness of the sensitivity analysis, we have selected two parameters sets with better simulation results than the default parameters for the six variables involved in this paper. They are the 24th and 47th sample points of the 189 valid simulations. Figure 8 compared the errors between observations and simulated values using default parameters with those using the 24th, 47th sampling parameters respectively. The variables we considered from left to right are the simulated values of $T_{\mathrm{G}}, R_{\mathrm{L}}, P_{\mathrm{L}}, P_{\mathrm{O}}, E_{\mathrm{L}}$, and $E_{\mathrm{O}}$. We can find that the errors of most variables between observations and the simulated values with the 24th, 47th sampling parameters are less than the errors between observations and the simulated values with default parameters (especially the $P_{\mathrm{O}}$ ), while both of the errors of $R_{\mathrm{L}}$ are similar. 

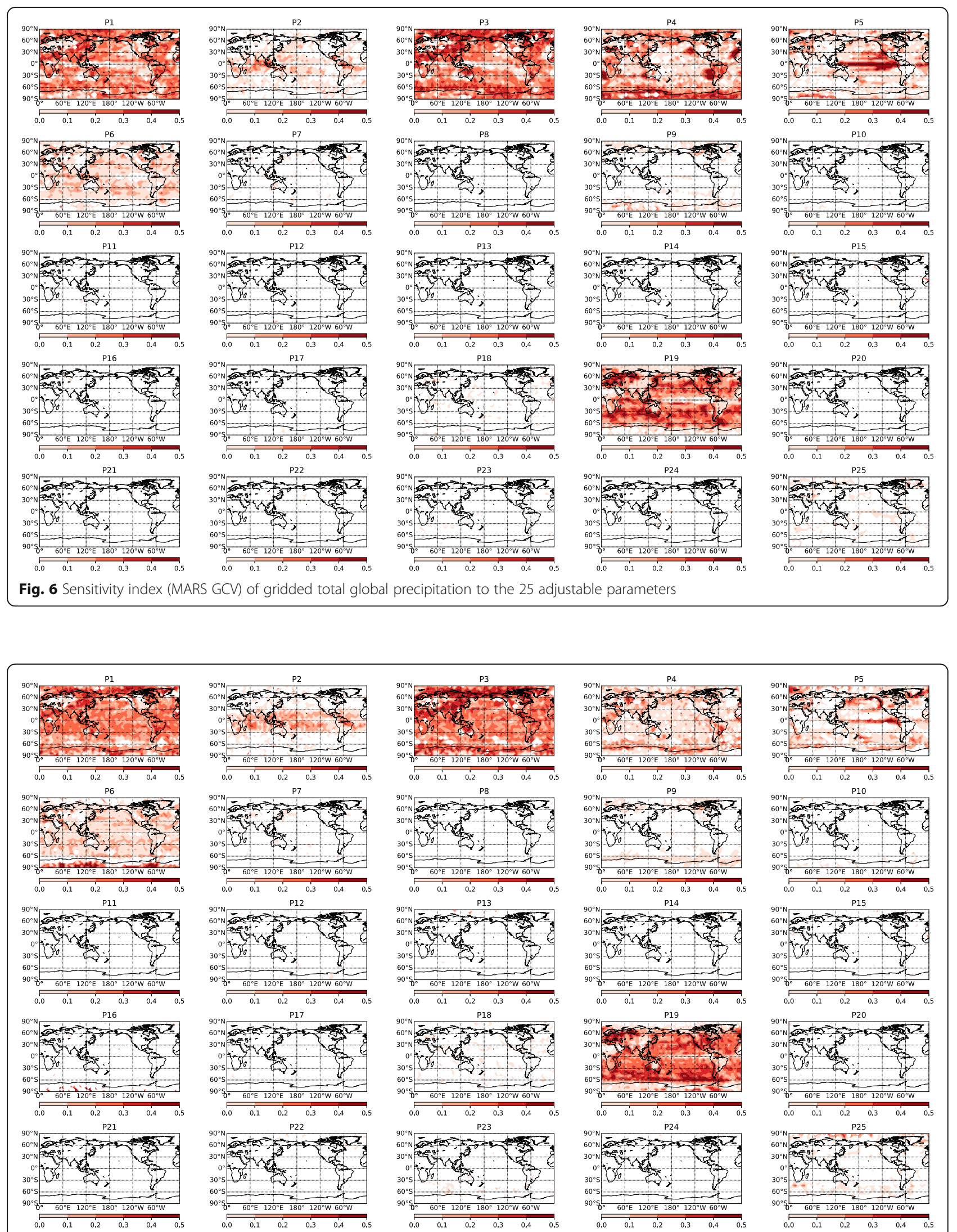

Fig. 7 Sensitivity index (MARS GCV) of gridded total global evaporation to the 25 adjustable parameters 


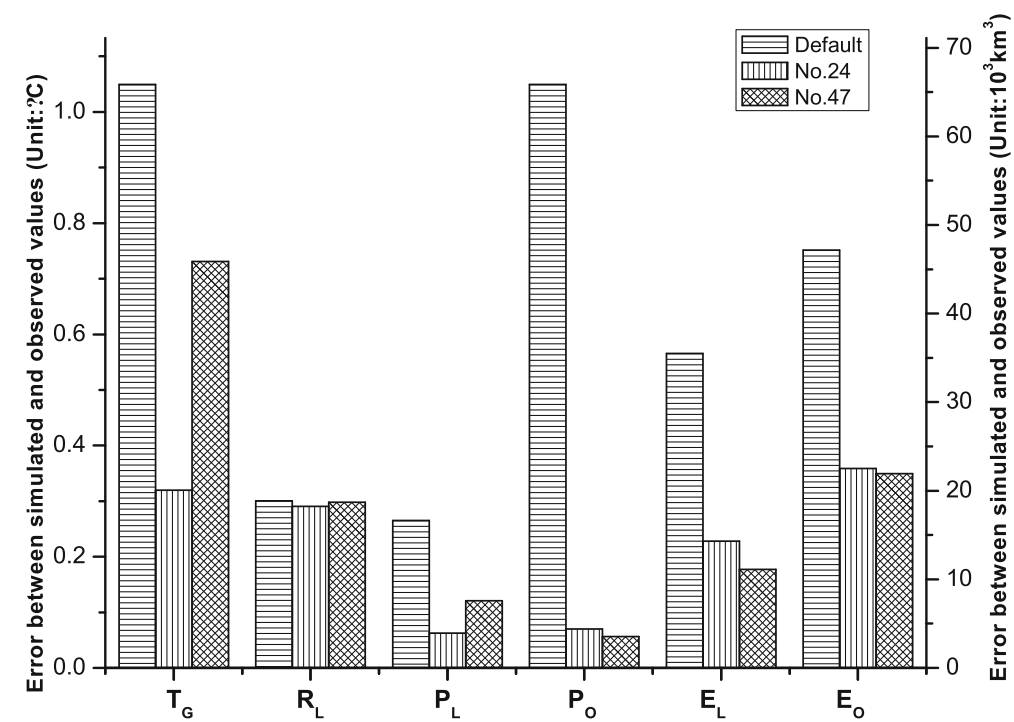

Fig. 8 Errors between the simulated valued of global mean near-surface air temperature $\left(T_{G}\right)$, total global runoff over land surface $\left(R_{L}\right)$, precipitation over land surface $\left(P_{\mathrm{L}}\right)$, precipitation over ocean $\left(P_{\mathrm{O}}\right)$, evapotranspiration over land surface $\left(E_{\mathrm{L}}\right)$, evaporation over ocean $\left(E_{\mathrm{O}}\right)$ by the default parameters, and the 24th and 47th sampling parameters and the corresponding observations

This shows that some of the errors can be greatly reduced by tuning the most sensitive parameters, while the remained model errors can be attributed to both model structure and model input.

\section{Conclusions}

In this study, we used SA methods to identify the most sensitive parameters for surface temperature, total precipitation, and total evaporation. The results of the three SA methods are consistent with each other: There are three to seven parameters that are deemed most sensitive in LOVECLIM depending on which climate variables are evaluated. In addition, the sensitive parameters for temperature and the water cycle components are different. Some of the sensitive parameters can affect temperature as well as climatic variable associated with the water cycle, and their effects are global. This result is very significant, as it reveals that if we would prefer to tune some of the adjustable parameters, we would need to focus on only a few of the parameters and not all of them. The spatial distribution of the parameter sensitivity is different. Parameter sensitivity has obvious differences at different latitudes and smaller differences between sea and land surfaces. In general, parameters related to longwave radiation have a greater impact on mid- and high latitudes, while parameters related to microphysics and the land-surface evapotranspiration have a greater impact on low latitudes. The screened parameters are generally consistent with the physical interpretations of the model parameters. Some parameters about snow/ice albedos and ocean seem only a little sensitive.
We would like to emphasize that the 25 parameters considered here do not comprise all tunable parameters in the LOVECLIM model. Similarly, we only selected some of the important output variables in LOVECLIM for the sensitivity analysis in this study. In the future, we are going to explore the sensitivity of more parameters in more complex Earth system models and compare sensitivity of more output variables with advanced analysis tools. However, the results obtained here can still provide a useful reference for anyone who would like to utilize a similar strategy. Furthermore, we also found that the simulation results of the climatic variables we selected from some of the sampled parameters are better than the results using the default parameters. It indicates that there is a great potential to improve climate simulation by optimizing the model parameters. We therefore recommend that parameters optimization should be used as one of the ways to improve the simulations of the climate system. To perform optimization in such cases, future studies must make use of more sophisticated optimization tools, including the surrogate modeling-based optimization approach, to save computational resources and, therefore, feasibly achieve a multi-objective optimization strategy for the model calibration of complex dynamic models.

In this study, the total global runoff simulated using the default parameters is $16.28 \times 10^{3} \mathrm{~km}^{3}(40.7 \%)$ lower than the total global runoff obtained from the ERA-40 reanalysis data. Meanwhile, the total global precipitation and evaporation from both land and sea surfaces are larger than those in the reanalysis data, implying a bias toward stronger global hydrological cycle compared to 
that of the real world. The biased hydrological cycle might be a possible reason for the $1{ }^{\circ} \mathrm{C}$ warmer global temperature and may lead to unknown distortions in Earth system simulations. It is almost impossible to reduce the error only through parameter tuning if the model physics is not properly represented. If the parameters of a physically incorrect model were forced to fit the observations, the interior processes in the model would be wrong as well, and the future climate projection might be untrustworthy. The reason for the biased hydrological cycle might be due to the oversimplified land-surface hydrological processes. This leads to the problem that no matter how the parameter values are perturbed, runoff is always negatively biased. This fact suggests that although parameter calibration is sometimes useful, it has limit in solving the model structure problem. Tuning the parameters, of course, does not have the ability to correct problematic or oversimplified model structures. Therefore, the model structure of LOVECLIM needs to be further improved, especially in terms of its hydrological circulation process.

\section{Additional file}

Additional file 1: Figures S1-S6. Sensitivity analysis results of current age (1951 to 2000 C.E.). Figures S7-S12. Sensitivity analysis results of preindustrial age (1701 to 1800 C.E.). (DOCX $7939 \mathrm{~kb})$

\section{Abbreviations}

DoE: Design of experiment; EMIC: Earth system model of intermediate complexity; ESM: Earth system models; GLP: Good lattice points; LBM: Landsurface bucket model; MARS: Multivariate adaptive regression splines; NWP: Numerical weather prediction; PCE: Polynomial chaos expansion; QMC: Quasi-Monte Carlo; RF: Random forests; SA: Sensitivity analyses; SPC: Sparse polynomial chaos; UQ-PyL: Uncertainty Quantification Python Laboratory

\section{Acknowledgements \\ Many thanks to Hugues Goosse in Georges Lemaître Centre for Earth and Climate Research (TECLIM), Earth and Life Institute (ELI), Université catholique de Louvain (UCL), Belgium, who helped us a lot in running the LOVECLIM model.}

\section{Authors' contributions}

QD proposed the topic, conceived, and designed the study. WG carried out the experimental study. YS analyzed the data and helped in their interpretation. JC and CX collaborated with the corresponding author in the construction of manuscript. HW carried out sensitivity analysis with the sparse PCE-based Sobol' method. All authors read and approved the final manuscript.

\section{Authors' information}

Not applicable

\section{Funding}

This work was supported by the Special Fund for Meteorological Scientific Research in Public Interest (GYHY201506002), the National Basic Research Program of China (No. 2015CB953703), the State Key Laboratory of Earth Surface Processes and Resource Ecology (No. 2017-KF-05), and the Fundamental Research Funds for the Central Universities-Beijing Normal University Research Fund (No. 2015KJJCA04).

\section{Availability of data and materials}

The datasets generated during and/or analyzed during the current study are available from the corresponding author on reasonable request.

\section{Competing interests}

The authors declare that they have no competing interests.

\section{Author details}

${ }^{1}$ State Key Laboratory of Earth Surface Processes and Resource Ecology, Faculty of Geographical Science, Beijing Normal University, Beijing 100875, China. ${ }^{2}$ Institute of Land Surface System and Sustainable Development, Faculty of Geographical Science, Beijing Normal University, Beijing 100875, China. ${ }^{3}$ Institute for Geophysics, University of Texas at Austin, 10100 Burnet Road (R2200), Austin, TX 78758-4445, USA.

Received: 29 November 2018 Accepted: 10 June 2019

Published online: 26 June 2019

\section{References}

Allen MR, Ingram WJ (2002) Constraints on future changes in climate and the hydrologic cycle. Nature 419:224

Bastidas LA, Hogue TS, Sorooshian S, Gupta H, Shuttleworth W (2006) Parameter sensitivity analysis for different complexity land surface models using multicriteria methods. J Geophys Res Atmos 111, D20101. https://doi.org/10. 1029/2005JD006377.

Breiman L (1996) Bagging predictors. Mach Learn 24:123-140

Breiman L (2001) Random forests. Mach Learn 45:5-32. https://doi.org/10.1023/a: 1010933404324

Brovkin V, Ganopolski A, Svirezhev Y (1997) A continuous climate-vegetation classification for use in climate-biosphere studies. Ecol Model 101:251-261

Chahine MT (1992) The hydrological cycle and its influence on climate. Nature 359:373-380

Claussen M, Ganopolski A, Schellnhuber J, Cramer W (2000) Earth system models of intermediate complexity. Glob Chang Newsl 41:4-6

Claussen M, Mysak L, Weaver A, Crucifix M, Fichefet T, Loutre M-F, Weber S, Alcamo J, Alexeev V, Berger A (2002) Earth system models of intermediate complexity: closing the gap in the spectrum of climate system models. Clim Dyn 18:579-586

Collins M, Booth BB, Harris GR, Murphy JM, Sexton DM, Webb MJ (2006) Towards quantifying uncertainty in transient climate change. Clim Dyn 27:127-147

Di Z, Duan Q, Gong W, Wang C, Gan Y, Quan J, Li J, Miao C, Ye A, Tong C (2015) Assessing WRF model parameter sensitivity: a case study with 5 day summer precipitation forecasting in the greater Beijing area. Geophys Res Lett 42: 579-587

Duan Q, Di Z, Quan J, Wang C, Gong W, Gan Y, Ye A, Miao C, Miao S, Liang X (2017) Automatic model calibration: a new way to improve numerical weather forecasting. Bull Am Meteorol Soc 98:959-970

Eby M, Weaver AJ, Alexander K, Zickfeld K, Abe-Ouchi A, Cimatoribus A, Crespin E, Drijfhout S, Edwards N, Eliseev A (2013) Historical and idealized climate model experiments: an intercomparison of Earth system models of intermediate complexity. Clim Past 9:1111-1140

Edwards NR, Marsh R (2005) Uncertainties due to transport-parameter sensitivity in an efficient 3-D Ocean-climate model. Clim Dyn 24:415-433

Efron B (1979) Bootstrap methods: another look at the jackknife. Ann Stat 7:1-26.

Eyring $V$ et al (2016) ESMValTool (v1.0) - a community diagnostic and performance metrics tool for routine evaluation of Earth system models in CMIP. Geosci Model Dev 9:1747-1802. https://doi.org/10.5194/gmd-9-17472016

Fanning AF, Weaver AJ (1997) A horizontal resolution and parameter sensitivity study of heat transport in an idealized coupled climate model. J Clim 10: 2469-2478

Friedman JH (1991) Multivariate adaptive regression splines. Ann Stat 19:1-67

Gan Y, Duan Q, Gong W, Tong C, Sun Y, Chu W, Ye A, Miao C, Di Z (2014) A comprehensive evaluation of various sensitivity analysis methods: a case study with a hydrological model. Environ Model Softw 51:269-285

Gent PR, Danabasoglu G, Donner LJ, Holland MM, Hunke EC, Jayne SR, Lawrence DM, Neale RB, Rasch PJ, Vertenstein M (2011) The community climate system model version 4. J Clim 24:4973-4991

Gong W, Duan Q (2017) An adaptive surrogate modeling-based sampling strategy for parameter optimization and distribution estimation (ASMOPODE). Environ Model Softw 95:61-75 
Gong W, Duan Q, Li J, Wang C, Di Z, Dai Y, Ye A, Miao C (2015) Multi-objective parameter optimization of common land model using adaptive surrogate modeling. Hydrol Earth Syst Sci 19:2409-2425

Gong W, Duan Q, Li J, Wang C, Di Z, Ye A, Miao C, Dai Y (2016a) An intercomparison of sampling methods for uncertainty quantification of environmental dynamic models. J Environ Inf 28:11-24

Gong W, Duan Q, Li J, Wang C, Di Z, Ye A, Miao C, Dai Y (2016b) Multiobjective adaptive surrogate modeling-based optimization for parameter estimation of large, complex geophysical models. Water Resour Res 52:1984-2008

Goosse H, Brovkin V, Fichefet T, Haarsma R, Huybrechts P, Jongma J, Mouchet A, Selten F, Barriat PY, Campin JM, Deleersnijder E, Driesschaert E, Goelzer H, Janssens I, Loutre MF, Maqueda MAM, Opsteegh T, Mathieu PP, Munhoven G, Pettersson EJ, Renssen H, Roche DM, Schaeffer M, Tartinville B, Timmermann A, Weber SL (2010) Description of the Earth system model of intermediate complexity LOVECLIM version 1.2. Geosci Model Dev 3:603-633. https://doi.org/10.5194/gmd-3-603-2010

Goosse H, Driesschaert E, Fichefet T, Loutre M-F (2007) Information on the early Holocene climate constrains the summer sea ice projections for the 21st century. Clim Past 3:683-692

Goosse H, Fichefet T (1999) Importance of ice-ocean interactions for the global ocean circulation: a model study. J Geophys Res Oceans 104:23337-23355

Goosse H, Selten F, Haarsma R, Opsteegh J (2001) Decadal variability in high northern latitudes as simulated by an intermediate-complexity climate model. Ann Glaciol 33:525-532

Goosse H, Selten F, Haarsma R, Opsteegh J (2002) A mechanism of decadal variability of the sea-ice volume in the northern hemisphere. Clim Dyn 19: $61-83$

Gupta HV, Razavi S (2018) Revisiting the basis of sensitivity analysis for dynamical earth system models. Water Resour Res. https://doi.org/10.1029/ 2018WR022668

Gutiérrez ÁG, Schnabel S, Contador JFL (2009) Using and comparing two nonparametric methods (CART and MARS) to model the potential distribution of gullies. Ecol Model 220:3630-3637

Hansen J, Sato M, Ruedy R, Lo K, Lea DW, Medina-Elizade M (2006) Global temperature change. Proc Natl Acad Sci U S A 103:14288-14293. https://doi. org/10.1073/pnas.0606291103

Hlawka E (1962) Zur angenäherten berechnung mehrfacher integrale. Monatshefte für Mathematik 66:140-151

Hourdin F, Mauritsen T, Gettelman A, Golaz J-C, Balaji V, Duan Q, Folini D, Ji D, Klocke D, Qian Y (2017) The art and science of climate model tuning. Bull Am Meteorol Soc 98:589-602

Huybrechts P (2002) Sea-level changes at the LGM from ice-dynamic reconstructions of the Greenland and Antarctic ice sheets during the glacial cycles. Quat Sci Rev 21:203-231

IPCC (2007) Climate Change 2007: The Scientific Basis. Contribution of Working Group I to the Fourth Assessment Report of the Intergovernmental Panel on Climate Change. Cambridge University Press, Cambridge

IPCC (2013) Climate Change 2013: The Scientific Basis. Contribution of Working Group I to the Fourth Assessment Report of the Inter-governmental Panel on Climate Change. Cambridge University Press, Cambridge

Johannesson G, Lucas D, Qian Y, Swile L, Wildey TM (2014) Sensitivity of precipitation to parameter values in the Community Atmosphere Model Version 5. Sandia report SAND2014-0829 Sandia National Laboratories, Albuquerque

Jones JAA (2014) Global hydrology: processes, resources and environmental management. Routledge, London

Korobov N (1959a) The approximate computation of multiple integrals. Dokl Akad Nauk SSSR 6:1207-1210

Korobov N (1959b) Computation of multiple integrals by the method of optimal coefficients. Vestn Mosk Univ, Ser Mat, Mekh, Astron, Fiz, Khim 4:19-25

Korobov N (1960) Properties and calculation of optimal coefficients. Dokl Akad Nauk SSSR 132:1009-1012

Levy S, Steinberg DM (2010) Computer experiments: a review. AStA Adv Stat Anal 94:311-324

Liu Y, Gupta HV, Sorooshian S, Bastidas LA, Shuttleworth WJ (2004) Exploring parameter sensitivities of the land surface using a locally coupled landatmosphere model. J Geophys Res: Atmos 109, D21101. https://doi.org/ 10.1029/2004JD004730.

Loutre MF, Mouchet A, Fichefet T, Goosse H, Goelzer H, Huybrechts P (2011) Evaluating climate model performance with various parameter sets using observations over the recent past. Clim Past 7:511-526. https://doi.org/ 10.5194/cp-7-511-2011

Mauritsen T, Stevens B, Roeckner E, Crueger T, Esch M, Giorgetta M, Haak H, Jungclaus J, Klocke D, Matei D, Mikolajewicz U, Notz D, Pincus R, Schmidt H, Tomassini $L$ (2012) Tuning the climate of a global model. J Adv Model Earth Syst 4. https://doi.org/10.1029/2012ms000154

Mouchet A, François L (1996) Sensitivity of a global oceanic carbon cycle model to the circulation and to the fate of organic matter: preliminary results. Phys Chem Earth 21:511-516

Murphy JM, Sexton DM, Barnett DN, Jones GS, Webb MJ, Collins M, Stainforth DA (2004) Quantification of modelling uncertainties in a large ensemble of climate change simulations. Nature 430:768-772

Neelin JD, Bracco A, Luo H, McWilliams JC, Meyerson JE (2010) Considerations for parameter optimization and sensitivity in climate models. Proc Natl Acad Sci 107:21349-21354

Opsteegh J, Haarsma R, Selten F, Kattenberg A (1998) ECBILT: a dynamic alternative to mixed boundary conditions in ocean models. Tellus A 50: 348-367

Pati YC, Rezaiifar R, Krishnaprasad PS (1993. IEEE) Orthogonal matching pursuit: recursive function approximation with applications to wavelet decomposition. In: Proceedings of 27th Asilomar conference on signals, systems and computers, pp 40-44

Petoukhov V, Claussen M, Berger A, Crucifix M, Eby M, Eliseev A, Fichefet T, Ganopolski A, Goosse H, Kamenkovich I (2005) EMIC Intercomparison project (EMIP-CO2): comparative analysis of EMIC simulations of climate, and of equilibrium and transient responses to atmospheric CO2 doubling. Clim Dyn 25:363-385

Quan J, Di Z, Duan Q, Gong W, Wang C, Gan Y, Ye A, Miao C (2016) An evaluation of parametric sensitivities of different meteorological variables simulated by the WRF model. Q J R Meteorol Soc 142:2925-2934

Ratto M, Castelletti A, Pagano A (2012) Emulation techniques for the reduction and sensitivity analysis of complex environmental models

Renssen H, Brovkin V, Fichefet T, Goosse H (2003) Holocene climate instability during the termination of the African humid period. Geophys Res Lett 30: 1184. https://doi.org/10.1029/2002GL016636.

Renssen H, Goosse H, Fichefet T, Brovkin V, Driesschaert E, Wolk F (2005) Simulating the Holocene climate evolution at northern high latitudes using a coupled atmosphere-sea ice-ocean-vegetation model. Clim Dyn 24:23-43

Ricciuto D, Sargsyan K, Thornton P (2018) The impact of parametric uncertainties on biogeochemistry in the E3SM land model. J Adv Model Earth Syst 10: 297-319. https://doi.org/10.1002/2017ms000962

Sanderson BM, Piani C, Ingram W, Stone D, Allen M (2008) Towards constraining climate sensitivity by linear analysis of feedback patterns in thousands of perturbed-physics GCM simulations. Clim Dyn 30:175-190

Santanello JA Jr, Peters-Lidard CD, Kumar SV (2011) Diagnosing the sensitivity of local land-atmosphere coupling via the soil moisture-boundary layer interaction. J Hydrometeorol 12:766-786

Sarrazin F, Pianosi F, Wagener T (2016) Global sensitivity analysis of environmental models: convergence and validation. Environ Model Softw 79: 135-152. https://doi.org/10.1016/j.envsoft.2016.02.005

Shahsavani D, Grimvall A (2011) Variance-based sensitivity analysis of model outputs using surrogate models. Environ Model Softw 26:723-730

Shahsavani D, Tarantola S, Ratto M (2010) Evaluation of MARS modeling technique for sensitivity analysis of model output. Procedia Soc Behav Sci 2: $7737-7738$

Sobol' IM (1993) Sensitivity estimates for nonlinear mathematical models. Math Modelling Comput Experiments 1:407-414

Steinberg D, Colla P, Martin K (1999). MARS User Guide. Salford Systems, San Diego

Sudret B (2008) Global sensitivity analysis using polynomial chaos expansions. Reliab Eng Syst Saf 93:964-979. https://doi.org/10.1016/i.ress.2007.04.002

Tan J, Cui Y, Luo Y (2017) Assessment of uncertainty and sensitivity analyses for ORYZA model under different ranges of parameter variation. Eur J Agron 91:54-62

Tang T, Reed P, Wagener T, Van Werkhoven K (2006) Comparing sensitivity analysis methods to advance lumped watershed model identification and evaluation. Hydrol Earth Syst Sci Discuss 3:3333-3395

Tebaldi C, Knutti R (2007) The use of the multi-model ensemble in probabilistic climate projections. Philos Trans Royal Soc London A: Mathematical, Physical and Engineering Sciences 365:2053-2075

Trenberth KE, Smith L, Qian T, Dai A, Fasullo J (2007) Estimates of the global water budget and its annual cycle using observational and model data. J Hydrometeorol 8:758-769 
Wang C, Duan Q, Tong CH, Di Z, Gong W (2016) A GUI platform for uncertainty quantification of complex dynamical models. Environ Model Softw 76:1-12

Williamson D, Goldstein M, Allison L, Blaker A, Challenor P, Jackson L, Yamazaki K (2013) History matching for exploring and reducing climate model

parameter space using observations and a large perturbed physics ensemble. Clim Dyn 41:1703-1729

Xiong S-y, X-m Z, J-b L, Wu Z-h (2010) Numerical simulation on the sensitivity of a heavy rain case to the random disturbances of land surface parameters. Torrential Rain Disasters 29:117-121

Zadeh FK, Nossent J, Sarrazin F, Pianosi F, van Griensven A, Wagener T, Bauwens W (2017) Comparison of variance-based and moment-independent global sensitivity analysis approaches by application to the SWAT model. Environ Model Softw 91:210-222. https://doi.org/10.1016/j.envsoft.2017.02.001

\section{Publisher's Note}

Springer Nature remains neutral with regard to jurisdictional claims in published maps and institutional affiliations.

\section{Submit your manuscript to a SpringerOpen ${ }^{\circ}$ journal and benefit from:}

- Convenient online submission

- Rigorous peer review

- Open access: articles freely available online

- High visibility within the field

- Retaining the copyright to your article

Submit your next manuscript at $\boldsymbol{\nabla}$ springeropen.com 